\title{
ANALYTICAL STUDIES ON PRECISION AND ACCURACY IN MICRODETERMINATION OF Pb , Cr, Cd AND Hg WITH EAB- CTAB AND EAB-TX COMPLEXES
}

\author{
Suparna Deshmukh \\ S. K. Gandhi College, Kada, Ashti, Dist. Beed \\ E-mail: suparna.deshmukh@gmail.com
}

\begin{abstract}
Precision and Accuracy studies have been carried out by forming a ternary complex between Eriochrome Azurol B, a Triphenylmethane dye; a cationic surfactant Cetyl Trimethyl Ammonium Bromide CTAB; a Non Ionic Surfactant Triton X-100 and some heavy metal ions mainly $\mathrm{Cd}(\mathrm{II}), \mathrm{Hg}$ (II) $\mathrm{Cr}$ (III)and $\mathrm{Pb}(\mathrm{II})$. The absorption spectra of Eriochrome Azurol B ,EAB; a triphenylmethane dye, has been studied by interaction with surfactants, Cetyl Trimethyl Ammonium Bromide, CTAB and Triton X-100 at different pH from ranging from $\mathrm{pH} 1.00$ to 12.00 . Absorption spectra showed a Hypsochromic shift in the presence of a surfactant. The decrease in the values of dissociation constants ( $\mathrm{pK}$ ), in the presence of surfactant, is observed which indicated the formation of water-soluble, stable, dye-surfactant complex. The composition of the stable dye-surfactant complex is determined which is found to be EAB:CTAB as 1:2 while the composition of chelates of $\mathrm{Cd}(\mathrm{II})$, and $\mathrm{Hg}(\mathrm{II})$ was found to be 1:2 in the absence of surfactant which changes to 1:1 in the presence of surfactant TritonX-100. Effect of foreign ions such as Chlorides; Nitrates and Sulphates of Sodium, Potassium, and Ammonium salts has been studied in detail. Bathochromic shift has been observed in the presence of CTAB and TX-100 with metal chelates under study. Surfactants have shown to increase the sensitivity of the color reactions of these complexes with greater solubility and higher stability. Various analytical parameters including the rate of color formation, effect of temperature and stability of color formation, the range of adherence to Beers Law, Molar Extinction constants, Sensitivity, were studied for all systems. Precision and Accuracy of the method suggested for micro determination of metal ions was determined and found out that method is both precise as well as accurate.
\end{abstract}

Keywords: Triphenylmethane Dye, Surfactant, Hypsochromic Shift, Bathochromic Shift, Stability, Sensitivity, Precision, and Accuracy.

(C) RASĀYAN. All rights reserved

\section{INTRODUCTION}

The property of formation of colored complexes has been successfully applied for the spectrophotometric estimation of metal ions since last few decades. The addition of quaternary salts to the deeply colored solution of dyes causes a marked color change with the change in the wavelength of maximum absorption. The hypsochromic shift is caused by short-range electrostatic forces on the surface of the micelle double layer. The purpose of the addition of surfactants to the dyes is thus to decolorize them. It is followed by Sign Rule which is an empirical statement ${ }^{1}$. The interesting property of the aggregates formed is their ability to form colored complexes with various cations. Another advantage is that the determination of micro amounts of metal ions can be done with much higher sensitivity in the presence of these long-chain quaternary salts. The reaction of triphenylmethane dyes with $4 \mathrm{f}$ and $5 \mathrm{f}$ metal ions have been a subject matter of study by several workers ${ }^{2-8}$. The systematic design of surfactants induced dye metal interactions leading to the sensitized photometric metal ion determination could obviously be facilitated by an accurate model of detail chemistry involved ${ }^{6-10}$. Complexation of $\mathrm{Cu}(\mathrm{II}), \mathrm{Fe}(\mathrm{II}) \& \mathrm{Al}(\mathrm{III})$ with Chrome Azurol $\mathrm{S}$ in the presence of nonionic surfactants was studied. ${ }^{11}$ The present investigation undertaken involves a detailed study of the interaction of surfactant Cetyl Trimethyl Ammonium Bromide and Triton X-100, with triphenylmethane dye Eriochrome Azurol B.

Rasayan J. Chem., 11(3), 1159-1165(2018)

http://dx.doi.org/10.31788/RJC.2018.1134007

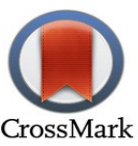


Composition of the dye-surfactant complex is determined by adding a varying concentration of surfactants to the dye solutions. Higher concentration of mineral salts prevents the micelle formation due to occurrence of inorganic anions which displace dye as counter ions ${ }^{12}$. Hence effect of mineral salts has been studied. The dye surfactant complexes thus formed was used to study complexation reactions of Cd (II) $\mathrm{Hg}$ (II), $\mathrm{Cr}(\mathrm{III})$ and $\mathrm{Pb}$ (II) and are compared with the complexation reaction of these metal ions with Eriochome Azurol B in absence of detergents too.

\section{EXPERIMENTAL}

Instruments : The absorption measurements were done on a UV Shimadzu spectrophotometer UV-240. Glass cuvettes of $1 \mathrm{~cm}$ thickness supplied with the instrument were used; distilled water blanks were used. For $\mathrm{pH}$ measurements, Elico pH meter LI-10 operated on 220volts stabilized AC mains were used, with a glass calomel electrode system.

Materials: All the reagents used were of BDH, Anal R grade purity. The surfactant, Cetyl Trimethyl Ammonium Bromide (CTAB), and Triton X-100 are prepared in $20 \%$ aq. methanol. The Dye solution was prepared in double distilled water by dissolving their purified samples and the standard solutions of metal solutions were prepared from different salts of $\mathrm{Cd}$ (II) $\mathrm{Hg}$ (II), and $\mathrm{Pb}$ (II), $\mathrm{Cr}$ (III) ions.

Procedure: Preparation of mixtures, measurements of absorbance, adjustment of $\mathrm{pH}$ etc. were carried out at room temperature. In all the experiments, CTAB and TX-100 solution was added to the reagent solutions which was kept for minimum $20 \mathrm{~min}$ for decolorization. The absorbance readings were recorded only after 30 minutes of the addition of the reactants, a time necessary for equilibration.

\section{Absorption Spectra}

\section{RESULTS AND DISCUSSION}

Absorption spectra of EAB solution were recorded from $\mathrm{pH} 1.0$ to 12.0. The spectral studies in the presence of ten times excess of CTAB and TX were also recorded from $\mathrm{pH} 1.0$ to 12.0. The $\lambda$ max values are summarized below in Table-1. Hypsochromic shift is observed at $\mathrm{pH}$ 5.0. Hence $\mathrm{pH}$ of study for using EAB and Surfactants is 5.0.

Table-1: $\lambda \max$ of EAB at Different $\mathrm{pH}$ Values

\begin{tabular}{c|c|c|c}
\hline $\mathrm{pH}$ & $\lambda \max \mathrm{nm}$ of EAB & $\lambda \max \mathrm{nm}$ Of EAB-CTAB & $\lambda$ max OF EAB-TX \\
\hline $1.0-2.0$ & 470 & 480 & 470 \\
\hline 3.0 & 460 & 510 & 480 \\
\hline 4.0 & 460 & 450 & 520 \\
\hline 5.0 & 450 & 420 & 415 \\
\hline $6.0-9.0$ & 420 & 425 & 460 \\
\hline $10.0-11.0$ & 425 & 610 & 430 \\
\hline 12.0 & 595 & 610 & 595 \\
\hline
\end{tabular}

\section{Dissociation Constant (pK Values) of EAB}

The EAB contains three replaceable protons in its molecule. Two of it correspond to to-COOH groups while the third corresponds to-OH group. The equilibrium reaction which occurs in the stepwise dissociation of $\mathrm{EAB}$ can be written as follows:

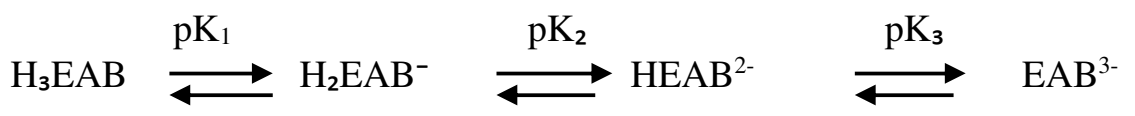

The above equilibrium reaction shows there exist three $\mathrm{pK}$ values for EAB. Experiments were carried out for the determination of $\mathrm{pK}$ values of $\mathrm{EAB}$ in the presence and absence of surfactant $\mathrm{CTAB}$ and TX. From the results, $\mathrm{pK}$ values obtained are recorded in Table-2. Several sets of solutions of suitable concentrations of dyes were prepared \& $\mathrm{pH}$ was adjusted from 1.0 to 12.0. Spectra of these solutions were recorded from $380 \mathrm{~nm}$ to $700 \mathrm{~nm}$. From the spectra, a graph was then plotted between absorbance and $\mathrm{pH}$ values at different $\lambda$ max obtained from spectra. The S-shaped curves are obtained where the lower part of it represents the molecular species and the upper portion represents the ionic species. From these spectra pK values were 
RASĀYAN $J$. Chem.

Vol. 11 | No. 3 |1159 - 1165 | July - September | 2018

determined both in absence as well as in the presence of CTAB and TX-100. The lowering of pK values in presence of $\mathrm{CTAB}$ and $\mathrm{TX}$ indicates their action on $\mathrm{EAB}$.

Table-2: Dissociation Constants of EAB

Lowering of pK values indicates the action of surfactants on $\mathrm{EAB}$.

\begin{tabular}{c|c|c|c}
\hline $\mathrm{pK}$ values & In absence of surfactant & In presence of CTAB & In presence of TX-100 \\
\hline $\mathrm{pK}_{1}$ & 3.20 & 2.70 & 2.90 \\
\hline $\mathrm{pK}_{2}$ & 5.69 & 5.04 & 5.60 \\
\hline $\mathrm{pK}$ & 11.13 & 10.84 & 11.00 \\
\hline
\end{tabular}

\section{The composition of EAB-CTAB and EAB-TX Complex}

The effect of varying concentration of CTAB on EAB absorbance was studied at $\mathrm{pH} 5.0$ and at $420 \mathrm{~nm}$. The absorbance of EAB decreases linearly up to a definite ratio of EAB:CTAB, as 1:1, is reached. After this point, the addition of a surfactant, even in excess amount did not alter the absorbance of EAB to any significant extent. Thus the complex formed can be represented as [EAB(CTAB)].The effect of varying concentration of TX on EAB absorbance was also studied at $\mathrm{pH} 5.0$ and at 530nm. The absorbance of EAB decreases linearly up to a definite ratio of EAB:TX, as 1:1, is reached. After this point, the addition of a surfactant, even in excess amount did not alter the absorbance of EAB to any significant extent. Thus this complex formed can be represented as $[\mathrm{EAB}(\mathrm{TX})]$.

\section{Effect of Mineral Salts}

Caiwen and Quingyue ${ }^{13}$ studied the effects of inorganic salts on the color reactions of triphenylmethane dyes in the presence of surfactants, which found to exert some sensitizing effect on the complex formation between TPM dyes and surfactants. The cations $\mathrm{K}^{+}, \mathrm{Na}^{+}, \mathrm{NH}_{4}^{+}$did not show any effect on the absorbance of the dye-detergent solution. Nitrates have shown some effect at $\mathrm{pH}$ 5.0, as the absorbance goes on increasing up to certain extent after which it remains unaltered. The mineral salts selected were the chlorides ( $\mathrm{KCl}, \mathrm{NaCl}$, and $\mathrm{NH}_{4} \mathrm{Cl}$ ), the nitrates $\left(\mathrm{KNO}_{3}, \mathrm{NaNO}_{3},\left(\mathrm{NH}_{4}\right) \mathrm{NO}_{3}\right.$ ), and sulfates $\mathrm{K}_{2} \mathrm{SO}_{4}, \mathrm{Na}_{2} \mathrm{SO}_{4}$, $\left(\mathrm{NH}_{4}\right)_{2} \mathrm{SO}_{4}$. To study this in detail, different concentration of salt solutions were added to $1.0 \times 10^{-3} \mathrm{M} \mathrm{EAB}$ solution containing $1.0 \times 10^{-2} \mathrm{M} \mathrm{CTAB}$ and TX-100 into it.

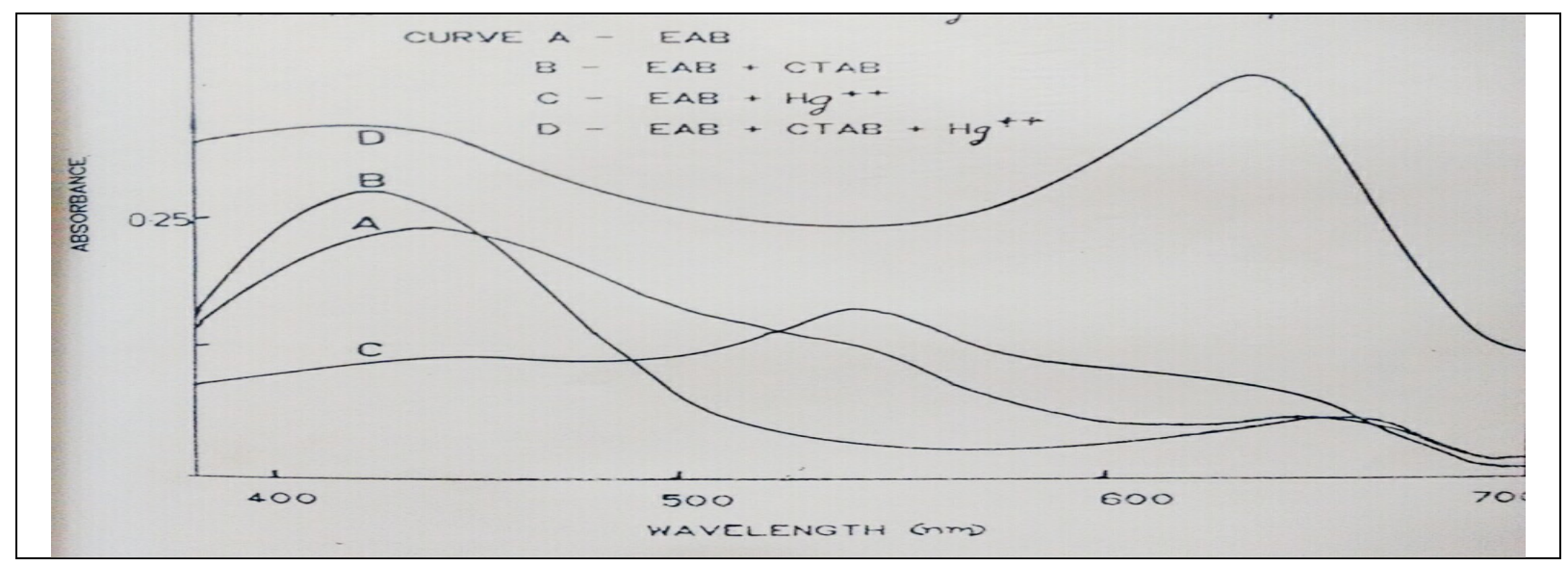

Fig.-1: Absorption Spectra Of Cd(II) in Absence and Presence of CTAB

\section{Dissociation Constant (pK Values) of EAB}

Table-2: Dissociation Constants of EAB

\begin{tabular}{c|c|c|c}
\hline $\mathrm{pK}$ values & In absence of surfactant & In presence of CTAB & In presence of TX-100 \\
\hline $\mathrm{pK}_{1}$ & 3.20 & 2.70 & 2.90 \\
\hline $\mathrm{pK}_{2}$ & 5.69 & 5.04 & 5.60 \\
\hline $\mathrm{pK}_{3}$ & 11.13 & 10.84 & 11.00 \\
\hline
\end{tabular}

Lowering of $\mathrm{pK}$ values indicates the action of surfactants on EAB. 


\section{Absorption Spectra of the Complexes}

Absorption spectra of EAB, EAB- metal ion, EAB - CTAB and EAB - metal ion - CTAB and that in presence of TX-100, were recorded at the $\mathrm{pH}$ of study. The nature of complexes formed between $\mathrm{EAB}$ and $\mathrm{Cd}$ (II) $\mathrm{Hg}$ (II), $\mathrm{Cr}$ (III)and $\mathrm{Pb}$ (II) has been studied in detail. A representative absorption spectrum is shown in the fig. to indicate the methodology used. The metal ions selected for the present study are susceptible to hydrolysis in the alkaline range. It was thus necessary to study the complex formation in the acidic range of $\mathrm{pH} 3.0$ to 6.0. The absorption spectra of metal complexes of EAB was studied in the absence as well as in the presence of CTAB and TX-100. The bathochromic shift and increase in the absorbance of complexes are attributed due to the dissociation of phenolic protons of the dye in presence of a surfactant.

Table-3: $\lambda$ max of EAB and its Chelates in the Absence as well as the Presence of CTAB at pH 5.0 and with $\mathrm{M}: \mathrm{L}$

\begin{tabular}{c|c}
\multicolumn{2}{c}{ as 1:2 } \\
\hline System & $\lambda$ max \\
\hline EAB & 460 \\
\hline EAB+ CTAB & 440 \\
\hline EAB + Hg(II) & 540 \\
\hline EAB +CTAB + Hg(II) & 630 \\
\hline $\mathrm{EAB}+\mathrm{Pb}(\mathrm{II})$ & 540 \\
\hline $\mathrm{EAB}+\mathrm{CTAB}+\mathrm{Pb}(\mathrm{II})$ & 630 \\
\hline $\mathrm{EAB}+\mathrm{Cd}(\mathrm{II})$ & 540 \\
\hline $\mathrm{EAB}+\mathrm{CTAB}+\mathrm{Cd}(\mathrm{II})$ & 640 \\
\hline $\mathrm{EAB}+\mathrm{Cr}(\mathrm{III})$ & 540 \\
\hline EAB + CTAB +Cr(III) & 640 \\
\hline $\mathrm{EAB}+\mathrm{TX}+\mathrm{Cd}$ & 590 \\
\hline $\mathrm{EAB}+\mathrm{TX}+\mathrm{Hg}$ & 630 \\
\hline
\end{tabular}

\section{The composition of the Chelates}

The stoichiometry of complexes is ascertained by Job's method of continuous variation at the pH $5.0 \& \lambda$ $\max$ and at the wavelength of study. The composition of the complexes at metal ions under study with EAB remains the same in the presence and in the absence of surfactants. From spectral studies, it was found that EAB forms complexes M:L ratios at 1:2 stoichiometric ratio in presence as well as in absence of $\mathrm{CTAB}$. The composition of the complexes formed in presence as well as in the absence of TX changes in case of $\mathrm{Cd}$, and $\mathrm{Hg}$ complexes. This change in nature of the complexes may be attributed due to the involvement of cationic micelles attachment to the neutral micelles attachment to the chelating positions of EAB.As these positions are already occupied by TX, another anion of the ligand must be involved in the complexation to fulfill the coordination sphere of the metal ion thus changing the composition from 1:1 to $1: 2$.

\section{Stability Constant}

The values of stability constants obtained as $\log \mathrm{K}$ values of chelates of metal ions under study are reported in Table-4.

\begin{tabular}{c|c|c|c}
\multicolumn{4}{c}{ Table-4: Composition and Stability Constant ( LogK) of Chelates } \\
\hline Chelates & $\lambda \max (\mathrm{nm})$ & $\begin{array}{c}\text { Composition } \\
\text { M:EAB:CTAB }\end{array}$ & $\begin{array}{c}\text { Log K value } \\
\text { By Job's method }\end{array}$ \\
\hline EAB $+\mathrm{Hg}(\mathrm{II})$ & 540 & $1: 2$ & 10 \\
\hline EAB+CTAB $+\mathrm{Hg}(\mathrm{II})$ & 630 & $1: 2: 2$ & 10.8 \\
\hline $\mathrm{EAB}+\mathrm{Pb}(\mathrm{II})$ & 540 & $1: 2$ & 9.9 \\
\hline EAB+CTAB $+\mathrm{Pb}(\mathrm{II})$ & 630 & $1: 2: 2$ & 10.7 \\
\hline $\mathrm{EAB}+\mathrm{Cd}(\mathrm{II})$ & 540 & $1: 2$ & 9.7 \\
\hline EAB+CTAB+Cd(II) & 640 & $1: 2: 2$ & 10.1 \\
\hline $\mathrm{EAB}+\mathrm{Cr}(\mathrm{III})$ & 540 & $1: 2$ & 9.5 \\
\hline EAB $+\mathrm{CTAB}+\mathrm{Cr}(\mathrm{III})$ & 640 & $1: 2: 2$ & 10.8 \\
\hline EAB $+\mathrm{TX}+\mathrm{Hg}(\mathrm{II})$ & 630 & $1: 1: 1$ & 10.72 \\
\hline EAB $+\mathrm{TX}+\mathrm{Cd}(\mathrm{II})$ & 590 & $1: 1: 1$ & 11.20 \\
\hline \multicolumn{4}{|c}{1162}
\end{tabular}


The results showed that the values of $\log \mathrm{K}$ in the presence of surfactants are greater than that in the absence. This is associated with the tendency of decrease in $\mathrm{pK}$ values, dissociation constants of dye EAB, in the presence of surfactants.

\section{Analytical Applications}

In all the experiments, a surfactant solution was added to EAB solution; which was then kept for at least $0.5 \mathrm{hr}$ for complete formation of dye - detergent complex, to which the metal ion solution was added. This sequence was fixed by carrying out an experiment by varying sequences of additions, but the above one sequence showed to give constant absorbance readings. The temperature was found to have little effect on color intensity from $25^{\circ} \mathrm{C}$ to $60^{\circ} \mathrm{C}$ and color was stable up to 3 to $4 \mathrm{hrs}$.

\section{pH Range of Stability}

A series of solutions of metal : reagent in ratio were prepared at different $\mathrm{pH}$ values. In the presence of surfactants, the ratio of EAB : Surfactant was kept in proportion 1:10. The absorbance was noted at the wavelength of the study of the systems. The $\mathrm{pH}$ - range within which the absorbance values do not change significantly is taken as the $\mathrm{pH}$ range of stability. It is reported in Table 5

\section{Beer's Law and Photometric Ranges}

The linearity between the absorbance of the chelates in the absence as well as in the presence of CTAB Vs concentration of metal ions was tested by varying the metal ions concentration and keeping the reagent concentration constant at the $\mathrm{pH}$ and wavelength of study selected for various chelate systems. The effective photometric range was evaluated by Ringbom plots which are a plot of the log of metal ion concentration Vs. $\%$ transmittance.

\section{Sandell's Sensitivity and Molar Absorptivity of the System}

The sensitivity of color reaction of the metal ion with EAB given by $\log \mathrm{Io} / \mathrm{It}=0.0001$, as defined by Sandell are listed below.

Table-5: pH range of stability, Concentration Range of Beer's Law \& effective Photometric Range, Sensitivity, and Molar Absorptivity at $\mathrm{pH}$ of study $=5.0$

\begin{tabular}{|c|c|c|c|c|c|c|}
\hline System & $\mathrm{pH}$ range & $\begin{array}{l}\text { Range of } \\
\text { Beer's law } \\
\text { In ppm }\end{array}$ & $\begin{array}{l}\text { Photometric } \\
\text { Range }\end{array}$ & $\begin{array}{c}\text { Sandell } \\
\text { Sensitivity } \\
\text { SX10 }\end{array}$ & $\begin{array}{c}\text { Molar } \\
\text { absorptivity } \\
\text { EmX10 } 10^{-3}\end{array}$ & $\lambda \max (\mathrm{nm}$ \\
\hline $\mathrm{EAB}+\mathrm{Hg}(\mathrm{II})$ & $3.2-4.4$ & $0.25-0.37$ & $0.22-0.64$ & 2.7 & 9.5 & 540 \\
\hline $\mathrm{EAB}+\mathrm{CTAB}+\mathrm{Hg}$ & $4.5-5.5$ & $1.88-4.28$ & $1.99-4.26$ & 5.0 & 40.0 & 630 \\
\hline $\mathrm{EAB}+\mathrm{Pb}(\mathrm{II})$ & $3.8-4.2$ & $1.1-1.5$ & $1.24-2.24$ & 2.8 & 10.6 & 540 \\
\hline $\mathrm{EAB}+\mathrm{CTAB}+\mathrm{Pb}$ & $4.5-5.5$ & $2.76-9.66$ & $2.76-9.66$ & 15.2 & 9.4 & 630 \\
\hline $\mathrm{EAB}+\mathrm{Cd}$ (II) & $4.2-4.8$ & $0.77-4.32$ & $1.65-2.36$ & 10.2 & 3.5 & 540 \\
\hline $\mathrm{EAB}+\mathrm{CTAB}+\mathrm{Cd}$ & $5.0-6.0$ & $0.75-3.99$ & $2.82-4.46$ & 17.9 & 5.83 & 640 \\
\hline $\mathrm{EAB}+\mathrm{Cr}(\mathrm{III})$ & $4.0-4.8$ & $0.52-1.22$ & $0.95-1.22$ & 3.2 & 5.3 & 540 \\
\hline $\mathrm{EAB}+\mathrm{CTAB}+\mathrm{Cr}$ & $4.5-5.5$ & $0.69-2.77$ & $1.15-1.95$ & 6.9 & 7.1 & 640 \\
\hline Cd(II)-EAB-TX & $5 .-6.5$ & $0.75-3.99$ & $2.82-4.46$ & 4.9 & 16.7 & 590 \\
\hline $\mathrm{Hg}(\mathrm{II})-\mathrm{EAB}-\mathrm{TX}$ & $4 .-6.0$ & $2.1-8.02$ & $3.23-5.49$ & 9.8 & 18.5 & 630 \\
\hline
\end{tabular}

Procedure for the Microspectrophotometric Determinations of $\mathrm{Pb}(\mathrm{II}), \mathrm{Cr}(\mathrm{III}), \mathrm{Cd}$ (II) and $\mathrm{Hg}(\mathrm{II})$ with EAB in the presence of surfactant CTAB and TX-10O

$\mathrm{pH}$ of $\mathrm{EAB}$ solution is adjusted containing that concentration of metal ion as mentioned under the effective photometric determination is also adjusted to $\mathrm{pH} 5.0$ and added to the EAB solution or modified EAB solution (the modified Dyes is prepared by adding five-fold excess of CTAB solution to EAB solution and keeping it for half an hour for the complete formation of dye-surfactant complex). Total volume was made up to $25 \mathrm{ml}$ with distilled water having $\mathrm{pH}$ adjusted to 5.0 and the absorbance of the solution is measured at its wavelength of study against the modified reagent solution as a blank. The amount of metal ion present in the unknown solution can then be obtained by comparing its absorbance from the calibration curve obtained 
RASĀYAN J. Chem.

Vol. 11 | No. 3 |1159 - 1165 | July - September | 2018

under similar conditions. The mean absorbance, mean deviation and relative mean deviation are also found out. The value of most probable analytical errors is determined with root to mean square deviation; for ten replicate determinations ranges between 0.0008 to 0.0037 at the confidence limit of $t=99.5 \%$. If the number of determinations is further increased that would subsequently decrease the value of ta. Consequently, a point would be reached when an increase in precision will be too small to justify the expenditure of labor, time and reagents involved in an increased number of determinations. On the basis of root mean square deviation $(\sigma)$; the most probable error $(\mathcal{E})$, the difference between the arithmetic mean $(\dot{X})$; and the true or most expected value $\left(\mathrm{X}_{\mathrm{t}}\right)$ of absorbance for the systems under study, conclusions are drawn. Precision and accuracy data calculated are given in the following table. The expected diminish in the probable errors would also decrease the level of confidence limit, hence ten replicate determinations have been done in present studies.

Table-6: Precision Data For Absorbance Measurement

\begin{tabular}{c|c|c|c|c|c}
\hline System & $\dot{\mathrm{X}}$ & $\sigma$ & $\varepsilon$ & $\dot{\mathrm{X}}-\varepsilon$ & $\dot{\mathrm{X}}+\varepsilon$ \\
\hline $\mathrm{EAB}+\mathrm{Hg}(\mathrm{II})$ & 0.793 & 0.008 & 0.0093 & 0.783 & 0.802 \\
\hline $\mathrm{EAB}+\mathrm{CTAB}+\mathrm{Hg}$ & 0.124 & 0.003 & 0.0035 & 0.119 & 0.126 \\
\hline $\mathrm{EAB}+\mathrm{Pb}(\mathrm{II})$ & 0.566 & 0.005 & 0.0058 & 0.560 & 0.572 \\
\hline $\mathrm{EAB}+\mathrm{CTAB}+\mathrm{Pb}$ & 0.076 & 0.002 & 0.0023 & 0.074 & 0.078 \\
\hline $\mathrm{EAB}+\mathrm{Cd}(\mathrm{II})$ & 0.537 & 0.006 & 0.0070 & 0.530 & 0.544 \\
\hline $\mathrm{EAB}+\mathrm{CTAB}+\mathrm{Cd}$ & 0.064 & 0.003 & 0.0035 & 0.0605 & 0.068 \\
\hline $\mathrm{EAB}+\mathrm{Cr}(\mathrm{III}$ & 0.469 & 0.005 & 0.0058 & 0.463 & 0.475 \\
\hline $\mathrm{EAB}+\mathrm{CTAB}+\mathrm{Cr}$ & 0.046 & 0.004 & 0.0046 & 0.041 & 0.050 \\
\hline $\mathrm{EAB}+\mathrm{TX}+\mathrm{Cd}$ & 0.024 & 0.001 & 0.0012 & 0.023 & 0.025 \\
\hline $\mathrm{EAB}+\mathrm{TX}+\mathrm{Hg}$ & 0.027 & 0.003 & 0.0035 & 0.024 & 0.030 \\
\hline
\end{tabular}

Table-7: Accuracy Data For Absorbance Measurement Expressed as $(\Delta<\varepsilon)$

\begin{tabular}{c|c|c|c|c}
\hline System & $\dot{\mathrm{X}}$ & $\mathrm{X}_{\mathrm{t}}$ & $\Delta=\mathrm{X}_{\mathrm{t}}-\dot{\mathrm{X}}$ & $\varepsilon$ \\
\hline $\mathrm{EAB}+\mathrm{Hg}(\mathrm{II})$ & 0.793 & 0.791 & -0.002 & 0.0093 \\
\hline EAB+CTAB+Hg & 0.124 & 0.122 & -0.002 & 0.0035 \\
\hline $\mathrm{EAB}+\mathrm{Pb}(\mathrm{II})$ & 0.566 & 0.561 & -0.005 & 0.0058 \\
\hline $\mathrm{EAB}+\mathrm{CTAB}+\mathrm{Pb}$ & 0.076 & 0.075 & -0.001 & 0.0023 \\
\hline $\mathrm{EAB}+\mathrm{Cd}(\mathrm{II})$ & 0.537 & 0.532 & -0.005 & 0.0070 \\
\hline $\mathrm{EAB}+\mathrm{CTAB}+\mathrm{Cd}$ & 0.064 & 0.065 & 0.001 & 0.0035 \\
\hline $\mathrm{EAB}+\mathrm{Cr}(\mathrm{III}$ & 0.469 & 0.470 & 0.001 & 0.0058 \\
\hline $\mathrm{EAB}+\mathrm{CTAB}+\mathrm{Cr}$ & 0.046 & 0.045 & -0.001 & 0.0046 \\
\hline $\mathrm{EAB}+\mathrm{TX}+\mathrm{Cd}$ & 0.024 & 0.024 & 0.000 & 0.0012 \\
\hline $\mathrm{EAB}+\mathrm{TX}+\mathrm{Hg}$ & 0.027 & 0.028 & 0.001 & 0.0035 \\
\hline
\end{tabular}

CONCLUSION

The mean absorbance, mean deviation, and relative mean deviation are calculated by taking ten repeated analysis with aliquots containing metal ions under study. Also, i) the Root Mean Square deviation, ii) the Most Probable Analytical error, and iii) the Difference Between Arithmetic Mean, and the true or Most Expected Value of the absorbance for the systems are studied. The Precision and Accuracy data recorded revealed that the method proposed is both precise as well as accurate. It is observed that the stabilities of the complexes have increased in the presence of surfactants. One of the most important applications of the colored complexes is its use in the spectrophotometric determination of the metal ions with organic dyes. The use of micelle-forming surfactants in increasing the sensitivity of the color reactions is one of the important aims of the study. The increased sensitivity of the system in the presence of surfactants is the net advantage for microspectrophotometric determination of metal ions using triphenyl methane dyes as reagents.

\section{REFERENCES}

1. C. F. Hartley and A.A Downay, J. Phys. Chem., 85, 835 (1984)

2. M. Jarosz, Wydawn Politech. Warsaw Pol., 53(1988) 
RASĀYAN J. Chem.

Vol. 11 | No. 3 |1159 - 1165 | July - September | 2018

3. M. N. Shtykov, Organ Reactivity. Analize., 3, 36, (1979)

4. R. K. Chernova, L. M. Kudrytseva, V. V. Belousova, L. K. Sukhova, Organ Reactivity Analize, 3, 16, (1979)

5. L. Cerkova, Surfactants Solution, 4(2), 1217, (1982)

6. T.S. West, R. M. Dognali, J. E. Chester and W. Bailay, Talanta, 51, 1359, (1968)

7. A.B. Zade; K. N. Munshi, K.L. Mitttal (ed) Proceedings International Conference on Surfactants in Solution, Plenum Press, 5 (Part II ), 713,(1988).

8. C. R. Vekhande, K. N. Munshi, J. Indian Chem.. Soc., 50,384(1973).

9. A. S. Mahakalkar, K. N. Munshi, Asian Journal of Chemistry, 6, 56(1994)

10. A. Ringbom, Zh. Analyt.Chem., 115, 332(1939), DOI: 10.1016/B978-0-444-98882-9.50007-4

11. V. Svoboda, V. Chromy, Talanta, 12, 431(1965), DOI: 10.1016/0039-9140(65)80259-4

12. Caiwen, Guo and Wang Quingyne, Huaxue Shiji, 6, 26(1985).

13. Juan A. Ocana, Manuel Callejon and Francisco Jose Barragan, Anal., 125, 1851(2000), DOI: 10.9790/5736-1106012934

14. M. Z.Salma Al-Kindy and Fakhr Eldin O. Suliman, Luminescence, 22(4), 294(2007).

15. I. S. Ahmed, A.S. Amin , Y.M. Issa , Spectrochimica Acta Part A, 64, 246(2006), DOI: 10.1016/j.saa.2005.06.044

16. Mohsen Keyvanfard, PWASET, 33, 2070, ( 2008)

17. A. S. Dhepe, A.B. Zade, E- Journal Of Chemistry, 8(3),1264(2011), DOI: 10.1155/2011/871685

18. H. Dezhampanah and R Firouzi, Int. Res. Phys. Chem., 45(2012), DOI: 10.1016/j.arabjc.2015.09.009

19. Renu Sharma, Ajar Kamal and Rakesh Kumar Mahajan, RSC Advances, 75(6),71692(2016), DOI: 10.1039/C6RA12056C

[RJC-4007/2018] 